\title{
Quality of Life in Patients with Multiple Myeloma: A Qualitative Study
}

\author{
Gitte Lee Mortensen ${ }^{1 *}$ and Morten Salomo
}

${ }^{1}$ Medical Anthropologist, Fynsgade 24, Aarhus C, Denmark

${ }^{2}$ Department of Haematology, Rigshospitalet, Blegdamsvej, Denmark

\begin{abstract}
Objective: Multiple myeloma (MM) accounts for approximately $15 \%$ of hematological cancers. Although still incurable, the prognosis of MM has much improved within the past two decades due to the use of high-dose chemotherapy (HDT) supported by autologous stem-cell transplantation (ASCT) for eligible patients and a variety of novel agents. How to use and sequence these new potent treatments is a growing challenge. While focus is on efficiency and tolerability, the ultimate goal is the reestablishment and preservation of patients' quality of life (QoL). This has increased the relevance of examining MM patient's QoL and experiences as long-term survivors. This qualitative study therefore aimed to gain in-depth knowledge about health related QoL in patients with relapsingremitting $M M(R R M M)$.
\end{abstract}

Methods: A literature study identified topics for individual in-depth qualitative interviews with eight Danish myeloma patients, four women and four men. Semi-structured interview guides were applied exploring the participants' experiences with the course of disease and treatment, its impact on their physical, cognitive and psychosocial QoL and functioning, and if they had unmet care needs. The interviews were transcribed verbatim and analysed using a narrative medical anthropological approach aiming to elicit significant patterns in the patients' perspectives on the impact of MM on their QoL.

Results: The participants had ambiguous perceptions of MM that was simultaneously seen as life menacing and manageable. Their physical and cognitive functioning was reduced from disease symptoms and treatmentrelated toxicity. Persistent peripheral neuropathy was considered particularly burdensome. The initial shock of receiving a cancer diagnosis was reduced by reassurance of the high manageability of MM. In the long run, the participants were able to lead 'fairly normal' lives but said their QoL was reduced by concerns about underlying disease, relapse and disability. Being able to uphold a social role and meaningful activities was crucial to their QoL. Overall, the participants did not discuss HRQoL issues with their oncologist, however, because the main focus in consultations is on cancer control.

Conclusion: Long-term QoL in patients with MM may be over-estimated. Their disease perspectives and priorities should be explored and taken into account when making treatment decisions. Newly diagnosed patients may have particular needs for emotional support and information about the improved manageability of MM.

Keywords: Multiple myeloma; Haematology; Cancer; Quality of life; Patient needs; Qualitative research

\section{Introduction}

Multiple myeloma (MM) is a hematologic cancer arising from the malignant transformation of the immunoglobulin-producing plasma cells of the bone marrow. MM accounts for approximately $15 \%$ of hematological cancers- $01 \%$ of all cancers- and the incidence in Europe is 5.72 per 100.000 , corresponding to approximately 27.500 new cases every year [1]. With aging populations in Europe, incidence rates are expected to rise considerably [2].

MM often involves much delayed diagnosis as the symptoms tend to be non-specific and slowly evolving. With a typical age at diagnosis at 65-70 years, general fatigue, weakness and bone pain are often misinterpreted as rheumatic or osteoporotic, for instance $[1,3,4]$. The four common MM symptoms include elevated calcium, renal failure, anemia and bone lesions (the CRAB criteria). In addition, reduced immune function may lead to frequent and severe infections [5].

Though still incurable, the prognosis of MM has much improved within the past two decades owing to the use of high-dose chemotherapy (HDT) supported by autologous stem-cell transplantation (ASCT) for eligible patients as well as novel agents such as Thalidomide, Bortezomib and Lenalidomide [5,6]. Recently, this positive development is accelerating with the introduction of immunotherapy and targeted agents like histone deacetylase (HDAC) inhibitors, immune checkpoint modulation and proteome recycling pathways [7]. How to use and sequence these new potent treatments is one of the growing challenges. While focus is on efficiency and tolerability, the ultimate goal must always be the reestablishment and preservation of patients' quality of life (QoL). While induction and consolidation therapy are established treatment periods, the value of continuous treatment and maintenance are not finally determined [8], especially with regard to their influence on QoL. This has increased the relevance of examining the long-term physical and psycho-social QoL of patients with relapsing-remitting myeloma (RRMM). Here we therefore investigate the QoL of patients with relapsed MM in their treatment free period without maintenance.

A literature study showed that physical functioning even in stable RRMM patients' may be significantly compromised and associated with

*Corresponding author: Gitte Lee Mortensen, Medical Anthropologist, Anthro Consult (Owner and Senior Researcher), Fynsgade 24, 8000 Aarhus C, Denmark Tel: +45 23964252; E-mail: glm@anthroconsult.dk

Received October 13, 2016; Accepted December 12, 2016; Published December 15 2016

Citation: Mortensen GL, Salomo M (2016) Quality of Life in Patients with Multiple Myeloma: A Qualitative Study. J Cancer Sci Ther 8: 289-293. doi: 10.4172/19485956.1000430

Copyright: ( 2016 Mortensen GL, et al. This is an open-access article distributed under the terms of the Creative Commons Attribution License, which permits unrestricted use, distribution, and reproduction in any medium, provided the original author and source are credited. 
reduced ability to carry out work, domestic chores and leisure activities. Symptoms and treatment-related adverse events have been shown to predominantly lead to fatigue and pain, with peripheral neuropathy (PN) particularly affecting many patients [9,10]. Quantitative assessments have also reported symptoms such as muscle weakness, bone lesions, depression, anxiety, insomnia, anaemia, infections, cognitive and sexual problems [2,10-12]. Factors such as female gender, advanced age, progressive disease and therapy exhaustion may also affect HRQOL in patients with RRMM [13]. It has been argued that symptoms and treatment side effects mainly affect QoL in relation to the impact on patients' activities and participation, emotional well-being and available support options $[4,14]$. Symptoms, disease progression or treatment response alone thus does not adequately reflect the overall health related QoL (HRQoL) in patients with MM [10,14]. Using qualitative methods, the present study aimed to examine in depth the patient perspective on RRMM in a Danish setting. The objective was to explore how these patients consider the impact of their symptoms on their QoL.

\section{Methods}

This study was based on a systematic literature study and individual qualitative interviews with eight patients with RRMM. The interview participants were recruited strategically by MS from the Department of Hematology, Rigshospitalet, Denmark. Data collection continued until saturation point although an equal number of men and women was required. Eligible patients had received at least one relapse treatment and had been in remission for at least three months at the time of interview. All invited patients agreed to participate. The patients had no significant co-morbidity and represented both sexes to capture any gender differences. The participants received written and oral study information underlining that participation was voluntary, might be interrupted at any time and that all data were treated anonymously following the research ethical standards. All participants gave informed consent and the study did not require ethics committee approval. The qualitative interviews were carried out in participants' homes or a conference room by GLM in the period of June 2015- March 2016.

The literature study identified relevant topics for an interview guide aiming to explore the QoL impact of MM. Medline, Embase, PsycInfo and Artikelbasen (for articles in Danish) were searched for literature published 2005-2015 using the key words: 'myelomatos'/multiple myeloma in combination with 'patient' and 'quality of life/Qol/HRQoL/ functioning, or psycho-social/burden. The semi-structured interview guide began with questions to the participants' current and previous partner, family and professional status. The participants then described their experiences with the MM diagnosis and subsequent disease course including periods of relapse, treatment and remission. Questions went on to focus on their physical, cognitive and psychosocial health-related Qol and functioning. Finally, their disease perceptions and hopes for the future were discussed [15] (link to the interview guide).

The interviews were transcribed verbatim and analysed using NVivo (QSR) software and a discourse theoretical approach to the relationship between language and construction of meaning [16]. The participants' statements were seen as an expression as well as an ongoing construction of the meaning and personal impact of living with MM. This approach is used to analyze a diversity of statements such that clusters of meaning are generated. It involves an exploration of the terminology used to speak about the subject and the ways in which it is related to other issues. Firstly, the data were thus coded into the topics that were raised during the discussions. Secondly, the most important themes within each topic were identified. Finally, the frequency of and connections between topics and themes were analysed. This generated a pattern of the relative meaning that the different topics and themes had for the participants when framing the impact of MM on their physical, emotional and social QoL. All methodological and analytical steps were discussed and alternative interpretations sought with the authors and with an additional anthropologist.

\section{Results}

At the time of the interview, the participants were aged between 67-76 years; all were pensioners, and all but a recent widower had a partner, grown children and grandchildren. The participants who were now in remission and without anti-myeloma treatment had previously received various types of MM treatment. Current supportive therapy with analgesics, bisphosphonates and anti-depressants was allowed (Table 1).

The participants were diagnosed with MM after presenting with pain or bone fracture. In some cases, diagnosis took several months of uncertainty with misdiagnosis and various tests before attaining specialist treatment. No participants suspected or had prior knowledge of $\mathrm{MM}$ and they were shocked with the diagnosis as the mere concept of cancer suggested a risk of imminent death. The following months, patients and their relatives had been very anxious. Subsequent reassurance depended much on the information they received about $\mathrm{MM}$ and management options. Being told that 'this is not a disease that you die from, but one that you die with' had been particularly crucial to their coping with MM.

\section{Treatment Experiences}

The six participants having received HDT found that this was by far the toughest treatment. All other treatments were described in less disturbing terms. With HDT, some fell sick from the initial treatments; some found the stem cell extraction or holding ice chips in the mouth agonising. HDT was described as a 'horrible experience' involving an 'unsettling feeling that they (the doctors) are killing everything' leading some patients to briefly consider 'if this was worth it at all. In most cases, HDT lead to hair loss, nausea, vomiting and diarrhea for 1 to $1 \frac{1}{2}$ months. Still, as efficacy ultimately took priority, and because the suffering was limited in time, no participants reclined receiving HDT again, if necessary.

The main treatment side effect was persisting PN experienced in two of three participants having received bortezomib and two in three treated with Thalidomide. These patients suffered from pain, hypoesthesia or paresthesia in their feet. Bortezomib and Thalidomide were therefore the only treatments that four participants rejected receiving again. Excepting those, the participants trusted their oncologists to find the best treatment option when need be and did not request much involvement in treatment decisions. The participants were mostly satisfied with their communication with the oncologist, though some wished they had received psychological support at the time of diagnosis. Many said they still anticipated controls with some apprehension.

\section{Patient quote 1: Quality of life impact of peripheral neuropathy}

"Physical and cognitive quality of life effects in multiple myeloma" Five participants said they had become prone to infections; some had been hospitalized several times with pneumonia. Four participants had PN; one suffered from cramps and six from pain in the joints 


\begin{tabular}{|c|c|c|c|c|c|c|}
\hline $\begin{array}{l}\text { Participant Male } \\
\text { (M)/ Female (F) }\end{array}$ & $\begin{array}{c}\text { Age at time of } \\
\text { interview (years) }\end{array}$ & $\begin{array}{l}\text { Personal status at } \\
\text { diagnosis }\end{array}$ & $\begin{array}{l}\text { Professional status } \\
\text { at diagnosis }\end{array}$ & $\begin{array}{c}\text { Year of } \\
\text { diagnosis }\end{array}$ & MM treatments & $\begin{array}{l}\text { Current IMWG } \\
\text { status }\end{array}$ \\
\hline M1 & 73 & $\begin{array}{l}\text { Married } 2 \text { children } 5 \\
\text { grand children }\end{array}$ & Self-employed & 2007 & $\begin{array}{l}1 \text { Line } 2007 \text { CyDex induction with stem cell } \\
\text { harvest and HD-treatment } 2 \text { Line } 2009 \text { local } \\
\text { irradiation } 3 \text { line } 2012 \text { VCD induction and HD } \\
\text { treatment } 4 \text { line } 2013 \text { Rd }\end{array}$ & CR since Nov. 2014 \\
\hline M2 & 76 & $\begin{array}{l}\text { Widowed } 2 \text { children } 5 \\
\text { grand children }\end{array}$ & Retired & 2011 & $\begin{array}{l}5 \text { line } 2012 \text { MPT } \\
6 \text { line } 2013 \text { Benda-VD } \\
7 \text { line } 2014 \text { Rd }\end{array}$ & $\begin{array}{l}\text { VGPR since Okt. } \\
\qquad 2015\end{array}$ \\
\hline M3 & 63 & $\begin{array}{l}\text { Divorced } 2 \text { children } \\
\text { ( } 1 \text { deceased }) 1 \text { grand } \\
\text { child }\end{array}$ & Employed & 2008 & $\begin{array}{l}8 \text { line } 2008 \text { CyDex induction + harvest + HD- } \\
\text { mel } 2009 \text { line } 2013 \text { local irradiation }\end{array}$ & CR since Nov. 2013 \\
\hline M4 & 73 & $\begin{array}{l}\text { Married } 2 \text { children } 1 \\
\text { grand child }\end{array}$ & Self-employed & 2005 & $\begin{array}{l}1 \text { line } 2005 \text { VAD induction + harvest + HD- } \\
\text { Mel } \\
2 \text { line } 2009 \text { Td induction + HD-mel II }\end{array}$ & $\begin{array}{l}\text { VGPR since Okt. } \\
\qquad 2010\end{array}$ \\
\hline F1 & 67 & $\begin{array}{l}\text { Married } 2 \text { children } 5 \\
\text { grand children }\end{array}$ & Retired & 2007 & $\begin{array}{l}\text { 1. line } 2007 / 8 \text { VAD induction + harvest + HD- } \\
\text { Mel 2. line } 2013 \text { VCDx } 3 \text { induction and HD } \\
\text { mel II 3. line } 2015 \text { Rdx } 3+\text { dex }\end{array}$ & $\begin{array}{l}\text { VGPR since June } \\
\qquad 2015\end{array}$ \\
\hline $\mathrm{F} 2$ & 67 & $\begin{array}{l}\text { Married } 2 \text { children } 4 \\
\text { grand children }\end{array}$ & Employed & 2007 & $\begin{array}{l}\text { 1. line } 2007 \text { CyDex induction + harvest + } \\
\text { HD-Mel I+II } \\
\text { 2. line } 2010 \mathrm{Td}+\mathrm{HD}-\mathrm{Mel} \text { III } \\
\text { 3. line } 2010 \text { local irradiation } \\
\text { 4. line } 2014 / 15 \mathrm{Td}+\mathrm{HD}-\text { Mel IV } \\
\text { 5. line } 2015 \text { local irradiation }\end{array}$ & PR since May 2015 \\
\hline F3 & 67 & $\begin{array}{l}\text { Married } 3 \text { children } \\
\text { ( } 1 \text { deceased }) 1 \text { grand } \\
\text { daughter }\end{array}$ & Employed & 2003 & $\begin{array}{l}\text { 1. line } 2003 \text { VAD/Cy-Dex induction + harvest } \\
+ \text { HD-Mel I } 2 \\
\text { 2. line } 2015 \text { V-MPx } 7 \\
\text { 3. line } 2015 \text { local irradiation }\end{array}$ & PR since July 2015 \\
\hline $\mathrm{F} 4$ & 74 & $\begin{array}{l}\text { Co-habiting partner } 2 \\
\text { children } 1 \text { grand child }\end{array}$ & Retired & 2011 & $\begin{array}{l}\text { 1. line } 2012 \mathrm{MPT} \times 8 \\
\text { 2. line } 2014 \text { local irradiation } \\
\text { 3. line } 2015 \mathrm{Rd} \times 7\end{array}$ & $\begin{array}{l}\text { VGPR since Okt. } \\
\qquad 2015\end{array}$ \\
\hline
\end{tabular}

IMWG: International Myeloma Working Group; CR: Negative immunofixation on the serum and urine and disappearance of any soft tissue plasma cytomas and $<5 \%$ plasma cells in bone marrow; VGPR: Serum and urine M-protein detectable by immunofixation but not on electrophoresis or $\geq 90 \%$ reduction in serum M-protein plus urine M-protein level $<100 \mathrm{mg} / 24 \mathrm{~h}$; PR: $\geq 50 \%$ reduction of serum M-protein and reduction in 24 hours urinary M-protein by $\geq 90 \%$ or to $<200 \mathrm{mg} / 24 \mathrm{~h}$ If the serum and urine M-protein are unmeasurable, $5 \mathrm{a} \geq 50 \%$ decrease in the difference between involved and uninvolved FLC levels is required in place of the M-protein criteria If serum and urine M-protein are not measurable, and serum free light assay is also not measureable, $\geq 50 \%$ reduction in plasma cells is required in place of M-protein, provided baseline bone marrow plasma cell percentage was $\geq 30 \%$. In addition to the above listed criteria, if present at base; CyDex : cyclophosphamide/dexamethasone; HDT: High-Dose Chemotherapy (with ASCT); ASCT: Autologous Stem-Cell Transplantation; VCD: Bortezomib/Cyclophosphamide/Dexamethasone; Rd: Lenalidomide/Dexamethasone; Mel: Melphalan; MPT: Melphalan/Prednisone/Thalidomide; Benda-VD/BVD: Bendamustine/Bortezomid/Dexamethasone; VAD: Vincristine/Doxorubicin/Dexamethasone; Td: Thalidomide/dexamethasone

Table 1: Participant characteristics.

or bone-mainly in their back or shoulders-leading sometimes to sleep disturbances. All participants had lost some mobility, physical strength and stamina reducing their ability to work, do house work and exercise, in particular. Some had recovered from severe loss of physical functioning following fractures or HDT with very negative impact on their QoL. The participants explained that this was mainly due to the fact that they attached identity, self-esteem and meaning to being active and able to use their craftsmanship around the house or to help out family members (males), caring for grandchildren or being fit and attractive (women).

Six participants felt their cognitive functioning had decreased with loss of short-term memory and concentration in particular. Only one found this reduced her daily functioning, though, and many were unsure if their reduced physical or cognitive abilities were due to MM, treatment or ageing.

\section{Patient quote 2: Physical functioning bring meaning to patients' lives}

"Psycho-social quality of life impact of multiple myeloma" In two of three participants who had retired due to MM, this had been a difficult change of everyday life. After the initial crisis, most said they had led 'fairly normal' lives outside of treatment, however. Today, the participants said the disease was not constantly worrying but that they always had 'an underlying consciousness of it'. Some said they had become emotionally vulnerable and that spouts of pain, for instance, might lead to worries about it being a symptom of 'something dangerous', i.e. relapsing disease. Still, when relapses had indeed occurred, most said they had had no premonition and reacted with renewed anxietyespecially at the prospect of another HDT.

\section{Patient quote 3: Multiple myeloma described as a lurking threat}

To some, this ambiguity between relative normality and underlying disease also involved a changed body perception. The women's selfconfidence was particularly affected by changes in appearance following treatment e.g. weight issues and hair loss. Both men and women mentioned having lost their libido varyingly affecting partner relations. To married participants, the course of disease was largely a shared experience with the partner emotionally and practically involved. Most participants were also close with their children and grandchildren. Still, female participants tended to retain some concerns for themselves in order to spare their loved ones from worrying. Two women had entirely concealed having MM from their aged parents. Unlike the men, women often mentioned a close friend as a main confidante.

The participants said the MM and risk of deterioration led them to prioritize positive and meaningful relations and activities more clearly. Only one woman worried about dying because her partner and grown children did not do well in life and still needed her support. To the remaining participants, the risk of disability and dependence on others was described as more menacing than death because being active and 
upholding an important social and familial role was crucial to their QoL.

\section{Discussion}

The MM diagnosis came as a shock to the participants who had no prior knowledge about this disease. Early information about the promising treatment options was crucial to reduce their anxiety. Today, all stressed that MM is not a disease you die from but one that you die with. In our analysis, this is a core phrase for understanding the ambiguous patient perspective on MM: any cancer is instinctively considered critical, but-to the surprise of many-the tolerable symptom burden and medical manageability enables patients to lead 'fairly normal lives' albeit with some reduced physical and cognitive functioning.

While HDT was indeed very challenging [4], only PN was described as persistently reducing the QoL of some patients. Aside from PN, MM was considered a 'strange disease that you cannot feel when outside of treatment', i.e. a potentially deadly disease without major symptoms in periods of remission. The patients had faith in the treatment options but from fear of relapse, they continuously felt uneasy with controls and potential symptoms. Though not a source of constant worries, the uncanny consciousness of underlying disease lead to emotional vulnerability, changed body image as well as to positive life priorities. As others have argued, living with RRMM involves an ever-shifting perspective between illness and wellness that sustains a state of uncertainty [17].

Our study suggests that upholding one's social role and keeping active were crucial to coping with MM and preserving normality which was decisive to the patients' QoL. Fear of disability had thus largely replaced the initial fear of dying. We therefore agree that the distress of symptoms is linked to the contexts in which they challenge patients' relations and activities $[4,9]$. In our study, the women particularly tried to spare their loved ones from worries which may explain why female patients may suffer more from disturbed role, isolation and emotional aspects [2].

Yet it is a limitation of our study that it may be biased by the majority of participants stating to have supporting partners and relatives and thus may not adequately reflect the experiences of low-functioning patients and those lacking supports. Selecting eligible participants may have implied a bias towards well-spoken patients with good physician rapports. Recall-bias may also involve an under-communication of the distress following diagnosis due to the participants' present knowledge about MM and their status of long-term survivors. Finally, while using qualitative methods allowed for an in-depth understanding of patient perspectives on RRMM, i.e. they provided analytically generalizable results, they are not statistically generalizable. This would require a larger sample of patients.

Our qualitative approach provided explanations of how and why symptoms affect the roles, relations and activities that patients find meaningful and crucial to their QoL. This study confirms the existence of an unmet need for emotional support and information, particularly at the time of diagnosis [2,18]. It also suggests a continued need for communication, not only about test results and treatment options, but also addressing patients' emotional concerns e.g. worries about role functioning and disability. Also, prophylactic treatment against infections should be considered as infections jeopardise patients' health and may trigger anxiety. Finally, the negative QoL impact of PN should be taken into consideration when making treatment decisions.

An increased integration of QoL measurement in clinical trials has also been suggested to focus more on patient-welfare as well as survival $[19,20]$. Our study confirms that patients do not always report HRQoL problems, mainly because the main focus in consultations is on the cancer control and management. This may contribute to physicians overestimating HRQoL in patients with MM [9]. Clinicians and patients have also been shown to have different treatment priorities with respect to improving life expectancy and QoL and that discordance may exist between their respective perceptions of symptoms and side effects [3]. Overall, and especially in the context of new MM treatments, patients' HRQoL and preferences should be increasingly considered in treatment choices.

\section{References}

1. Mühlbacher AC, Lincke HJ, Nübling M (2008) Evaluating patients' preferences for multiple myeloma therapy, a discrete-choice-experiment. GMS Psychosoc Med 5: 10.

2. Molassiotis A, Wilson B, Blair S, Howe T, Cavet J et al. (2011) Unmet supportive care needs, psychological well- being and quality of life in patients living with multiple myeloma and their partners. Psycho oncol 20: 88-97.

3. Mühlbacher AC, Nübling M (2011) Analysis of physicians' perspectives versus patients' preferences: Direct assessment and discrete choice experiments in the therapy of multiple myeloma. Eur J Health Econ 12: 193-203.

4. Potrata B, Cavet J, Blair S, Howe T, Molassiotis A (2011) Understanding distress and distressing experiences in patients living with multiple myeloma: An exploratory study. Psycho oncol 20:127-134.

5. Sonneveld P, Verelst SG, Lewis P, Gray-Schopfer V, Hutchings A, et al. (2013) Review of health-related quality of life data in multiple myeloma patients treated with novel agents. Leukemia 27: 1959-1969.

6. Liwing J, Uttervall K, Lund J, Aldrin, Blimark A, et al. (2014) Improved survival in myeloma patients: starting to close in on the gap between elderly patients and a matched normal population. Br J Haematol 164: 684-693.

7. Anreddy N, Hazlehurst LA (2016) Targeting intrinsic and extrinsic vulnerabilities for the treatment of multiple myeloma. J Cell Biochem 118: 15-25.

8. Facon T (2015) Maintenance therapy for multiple myeloma in the era of nove agents. Hematology Am Soc Hematol Educ Program 1: 279-285

9. Boland E, Eiser C, Ezaydi Y, Greenfield DM, Ahmedzai SH, et al. (2013) Living with advanced but stable multiple myeloma: A study of the symptom burden and cumulative effects of disease and intensive (hematopoietic stem cell transplant-based) treatment on health-related quality of life. J Pain Symptom Manage 46: 671-679.

10. Baz R, Lin HM, Hui AM, Harvey RD, Colson K, et al. (2015) Development of a conceptual model to illustrate the impact of multiple myeloma and its treatment on health-related quality of life. Support Care Cancer 23: 2789-2797.

11. Shi Q, Wang XS, Shah N (2014) Prevalence of high symptom burden and its impact on functioning and quality of life in patients with multiple myeloma 3-9 months following autologous transplant. J Clin Oncol 32 (suppl abstr e19580).

12. Jordan K, Proskorovsky I, Lewis P, Ishak J, Payne K, et al. (2014) Effect of general symptom level, specific adverse events, treatment patterns, and patient characteristics on health-related quality of life in patients with multiple myeloma: Results of a European, multicenter cohort study. Support Care Cancer 22: 417-426.

13. Dimopoulos MA, Palumbo A, Hajek R, Kropff M, Petrucci MT, et. al. (2014) Factors that influence health-related quality of life in newly diagnosed patients with multiple myeloma aged $>65$ years treated with melphalan, prednisone and lenalidomide followed by lenalidomide maintenance: Results of a randomized trial. Leuk Lymphoma. 55: 1489-1497.

14. Osborne TR, Ramsenthaler C, de Wolf-Linder S, Schey SA, Siegert RJ, et al (2014) Understanding what matters most to people with multiple myeloma: A qualitative study of views on quality of life. BMC Cancer 14: 496.

15. Kvale S (1996) Interviews. An introduction to qualitative research interviewing London: Sage Publications.

16. Winther Jorgensen M, Phillips L (1999) Diskursanalyse som teori og metode Roskilde: Roskilde University Press.

17. Maher K, De Vries K (2011) An exploration of the lived experiences of individuals with relapsed Multiple Myeloma. Eur J Cancer Care 20:267-275 
Citation: Mortensen GL, Salomo M (2016) Quality of Life in Patients with Multiple Myeloma: A Qualitative Study. J Cancer Sci Ther 8: 289-293. doi: 10.4172/1948-5956.1000430

18. Lamers J, Hartmann M, Goldschmidt H, Brechtel A, Hillengass J, et al. (2013) Psychosocial support in patients with multiple myeloma at time of diagnosis: Who wants what? Psycho oncol 22: 2313-2320.

19. Johnsen AT, Tholstrup D, Petersen MA, Pedersen L, Groenvold M (2009) Health related quality of life in a nationally representative sample of haematological patients. Eur J Haematol 83: 139-148

20. Kvam AK, Fayers P, Hjermstad M, Guldbrandsen N, Wisloff F (2009) Health-related quality of life assessment in randomised controlled trials in multiple myeloma: A critical review of methodology and impact on treatment recommendations. Eur J Haematol 83: 279-289. 